\title{
DO RECONHECIMENTO VOLUNTÁRIO DE PATERNIDADE OU MATERNIDADE SOCIOAFETIVA NA CERTIDÃO DE NASCIMENTO
}

\author{
Giovana Bresqui Andrade; Giovana Yuki Trukiti, Ana Augusta Rodrigues Westin Ebaid. \\ Universidade do Oeste Paulista- UNOESTE, Curso de Direito, Presidente Prudente, SP. E-mail: \\ giovanabandrade@hotmail.com
}

\section{RESUMO}

O conceito de família vem sofrendo inúmeras mudanças e ampliações em seu campo de entendimento, sendo atualmente considerado um local onde se constrói os valores mais importantes, e devido a essas constantes mudanças surgiram o Direito Multiparental, que é mais uma forma de acolher as diversas formas de unidades familiares atuais. No presente trabalho tem a finalidade de analisar seu novo conceito e a filiação multiparental, que vem sendo amplamente debatido e aplicado de forma mais recorrente no Direito de Família, através de uma ampla pesquisa jurídica, jurisprudencial e doutrinária, analisamos a filiação multiparental e seus julgados, de forma a explanar todas as teses e conceitos dados a tal direito. A metodologia constou de levantamento bibliográfico e os dados foram examinados com a aplicação do método hipotéticodedutivo. A principal mudança estudada e debatida foi nas Certidões de Nascimento, onde agora é possível efetuar a melhor satisfação da criança ao obter o nome de dois pais ou duas mães, pois leva em consideração a criação e não apenas a genética, deixando de lado os laços biológicos e satisfazendo a afetividade.

Palavras-chave: Multiparentalidade, Família, Afetividade, Filiação.

\section{FROM THE VOLUNTARY RECOGNITION OF PATERNITY OR SOCIO-AFFECTIVE MATERNITY ON THE BIRTH CERTIFICATE}

\begin{abstract}
The concept of the family has undergone numerous changes and extensions in its field of understanding, being nowadays considered a place where the most important values are built, and due to these constant changes have arisen the Multiparental Law, which is another way of welcoming the various forms of current household units. This paper aims to analyze its new concept and multiparental affiliation, which has been widely debated and applied more frequently in Family Law, through extensive legal, jurisprudential and doctrinal research, we analyze the multiparental affiliation and its judges, in order to explain all the theses and concepts given to this right. The methodology consisted of a bibliographical survey and the data were examined with the hypothetical-deductive method. The main change studied and debated was in the Birth Certificates, where it is now possible to make the best satisfaction of the child when obtaining the name of two parents or two mothers, since it takes into account the creation and not only the genetics, leaving aside the bonds and satisfying affectivity.
\end{abstract}

Keywords: Multiparentality, Family, Affiliation, Membership. 


\section{INTRODUÇÃO}

O significado de família passou por diversas alterações com o passar dos anos, devido a novas interpretações e adequações ao meio atual. A Constituição de 1988 protege a família em si abrangendo também as novas características referentes às transformações da sociedade.

A família passou a se enquadrar como um instrumento de crescimento pleno e estável para seus membros, deixando de lado o antigo princípio adotado pelo Brasil na qual tinha como característica a concentração do poder familiar inteiramente na figura paterna, tornando a mulher como portadora da função de cuidar dos afazeres domésticos, e se preocupar com a criação dos filhos que era suportada apenas por ela.

O presente trabalho aborda a filiação multiparental, no qual esse modelo abordado leva em consideração o princípio da dignidade da pessoa humana e a afetividade como valor jurídico principal para a filiação, atuando de um jeito mais amplo e que englobe muito mais casos.

Verifica-se que, a tempos as famílias que não se enquadram nos modelos antes considerados tradicionais, se encontravam carentes de uma legislação específica que as envolvessem.

Importante ressaltar o fato de o tema retratar muito mais que uma simples filiação, e mesmo que não haja uma lei específica, isso não constitui impeditivo para aceitação da multiparentalidade.

\section{METODOLOGIA}

Trata-se de um levantamento bibliográfico, em que se busca uma análise do tema a partir de obras já publicadas, propondo um confronto de ideias. Os dados foram examinados com a aplicação do método hipotético-dedutivo, isto é, partindo do geral para o particular e as informações coletadas analisadas e confrontadas de forma dialética.

Foram utilizados para a realização deste artigo, livros de doutrina, artigos de revistas especializadas, legislações, jornais e demais documentos que se mostraram úteis e concernentes ao tema.

\section{DA MULTIPARENTALIDADE}

O conceito de família sofreu inúmeras alterações ao longo do tempo apresentando-se como um modelo de grande prestígio. Porém, a família contemporânea, muitas vezes renegada pela sociedade conservadora, vem se distinguindo dessa concepção de família adquirindo uma concepção variada, igualitária e com base a filiação afetiva surgindo à possibilidade de discussão sobre a multiparentalidade.

Multiparentalidade é a possibilidade jurídica conferida ao genitor biológico e/ou do genitor afetivo de invocarem os princípios da dignidade da pessoa humana e da afetividade para que uma criança tenha em seu registro civil de nascimento o nome de dois pais e / ou duas mães, onde o afeto se sobrepõe ao consanguíneo, dando assim o direito de inclusão no registro civil de mais de dois pais ou mais de duas mães, fazendo garantida a manutenção ou o estabelecimento de vínculos parentais. Para Kirch \& Copatti (2013, p. 339) a multiparentalidade significa a legitimação da paternidade/maternidade do padrasto ou madrasta que ama, cria e cuida de seu enteado (a) como se seu filho fosse, enquanto que ao mesmo tempo o enteado (a) o ama e o(a) tem como pai/mãe, sem que para isso, se desconsidere o pai ou mãe biológicos.

Dignidade da pessoa humana e multiparentalidade têm estreita relação, já que a segunda é uma das formas de concretização da primeira. Percebemos, portanto, que é possível a formação de vínculos socioafetivos parentais por toda a vida, ou a descoberta de liames biológicos a qualquer tempo. Se o ordenamento jurídico transmudou-se para o viés personalista com a 
finalidade de tutelar a pessoa humana de forma mais concreta e abrangente possível, deve reconhecer a possibilidade da cumulação parental, para que o assento de nascimento reflita a exata realidade daquela pessoa, que no mundo da vida, tem múltiplas vinculações parentais, das mais diversas ordens. (TEIXEIRA; RODRIGUES, 2010, p. 102)

Importante ressaltar que a Constituição Federal (BRASIL, 1988) traz um conceito de família, que faz jus a possibilidade debatida neste artigo:

art. 226. A família, base da sociedade, tem especial proteção do Estado. [...]

$\S$ 3ㅇ Para efeito da proteção do Estado, é reconhecida a união estável entre o homem e a mulher como entidade familiar, devendo a lei facilitar sua conversão em casamento.

$\S 4$ ㅇ Entende-se, também, como entidade familiar a comunidade formada por qualquer dos pais e seus descendentes. [...]

Maria Berenice Dias (2013, p. 385) sustenta que com o avanço da Medicina, que possibilitou as concepções geneticamente assistidas, não se pode mais admitir apenas a biparentalidade da filiação, devendo-se acolher a multiparentalidade e a biparentalidade. Assim a multiparentalidade decorre de uma ampliação dos conceitos de família e parentalidade, que surge diante do contexto da contemporaneidade e do surgimento de novos valores.

Para a ilustre desembargadora o direito da criança ou adolescente ter retratado em seu assento de nascimento o espelho de sua família constitui elemento essencial para a formação e desenvolvimento de sua identidade pessoal, familiar e social. Sua identificação no mundo é indissociável daqueles que fazem parte da sua história, dos quais carrega o DNA em sua alma. E para que haja a concretização desse direito - de ordem fundamental e personalíssima - somente é possível com o reconhecimento judicial da família multiparental, mediante a fiel reprodução desta realidade no registro de nascimento.

Por consequência da discussão que o presente tema acarretou ao mundo jurídico, a possibilidade de inserir na certidão de nascimento o nome de dois pais e uma mãe ou um pai e duas mães resultaram grande discrepância no meio. Primeiro documento do brasileiro, a certidão de nascimento tradicional continha a filiação da criança com o nome do pai em cima e, logo abaixo, o da mãe. No entanto, as relações de afeto têm configurado a estrutura das famílias e também a do documento oficial. Deste modo, decisões judiciais abriram novos caminhos para que coexista no registro civil dois pais e uma mãe ou um pai e duas mães, sendo esta a definição de famílias multiparentais.

A primeira decisão que deferiu a mudança no registro civil, aceitando assim, o conceito de multiparentalidade ocorreu em Ariquemes, quando a juíza Deisy Cristhian Lorena de Oliveira Ferraz proferiu sentença reconhecendo a multiparentalidade em demanda de investigação de paternidade cumulada com anulatória de registro (RONDÔNIA, 2012) em face de dois pais no seu registro de nascimento (o biológico e o socioafetivo). Ao decidir, ponderou a juíza:

[...] a pretendida declaração de inexistência do vínculo parental entre a autora e o pai registro afetivo fatalmente prejudicará seu interesse, que diga-se, tem prioridade absoluta, e assim também afronta a dignidade da pessoa humana. Não há motivo para ignorar o liame socioafetivo estabelecido durante anos na vida de uma criança, que cresceu e manteve o estado de filha com outra pessoa que não o seu pai biológico, sem se atentar para a evolução do conceito jurídico de filiação, como muito bem ponderou a representante do Ministério Público em seu laborioso estudo (RONDÔNIA, 2012).

Esta decisão gerou e foi base de estudos para juristas da PONTIFÍCA UNIVERSIDADE CATÓLICA DE MINAS GERAIS (2012) em um artigo denominado "Averbação da Sentença de Multiparentalidade: Aplicabilidade". Neste estudo, afirma-se a possibilidade de se reconhecer a multiparentalidade, em face dos princípios da Dignidade da Pessoa Humana e da Liberdade, considerando a existência tridimensional do ser humano. 


\section{NOVAS REGRAS DE REGISTRO DE NASCIMENTO}

Como consequência do estudo e discussão sobre o assunto exposto neste artigo o CONSELHO NACIONAL DE JUSTIÇA (2017) publicou no dia 17 de novembro de 2017 o Provimento no 63 que institui regras para emissão, pelos cartórios de registro civil, da certidão de nascimento, casamento e óbito. Entre as medidas adotadas, esta a possibilidade de reconhecimento voluntário da maternidade e paternidade socioafetiva, que até então era possível apenas por decisões judiciais em poucos Estados que continham normas reguladoras sobre o assunto.

No registro de nascimento, pessoas que contenham laços afetivos com a criança e se apresentem para o registro do bebê voluntariamente como pais ou mães poderão ter os mesmos direitos legais e obrigações que os pais biológicos ou adotivos, porém devendo ser feito com o consentimento do pai ou da mãe do menor se houver a ausência do juiz, e ser solicitado por maior de 18 anos. Sendo assim, a madrasta, padrasto ou um companheiro de um dos pais da criança pode ser reconhecido perante o cartório de registro civil e ter seu nome identificado no documento, podendo a certidão conter o nome de até dois pais e duas mães e não havendo diferença jurídica entre eles. O pedido é irrevogável e só poderá ser desconstituído pela via judicial.

Nestes termos os Tribunais começaram a reconhecer a multiparentalidade e a possibilidade de reconhecer na certidão de nascimento a filiação sociafetiva conforme decisão do TRIBUNAL DE JUSTIÇA DO ESTADO DE SÃO PAULO (BRASIL, 2015) em decisão do magistrado Alcides Leopoldo e Silva Júnior:

MATERNIDADE SOCIOAFETIVA Preservação da Maternidade Biológica Respeito à memória da mãe biológica, falecida em decorrência do parto, e de sua família - Enteado criado como filho desde dois anos de idade Filiação socioafetiva que tem amparo no art. 1.593 do Código Civil e decorre da posse do estado de filho, fruto de longa e estável convivência, aliado ao afeto e considerações mútuos, e sua manifestação pública, de forma a não deixar dúvida, a quem não conhece, de que se trata de parentes - A formação da família moderna não-consanguínea tem sua base na afetividade e nos princípios da dignidade da pessoa humana e da solidariedade Recurso provido. (TJ-SP APL: 64222620118260286 SP 0006422-26.2011.8.26.0286, Relator: Alcides Leopoldo e Silva Júnior, Data de Julgamento: 14/08/2012, 1a Câmara de Direito Privado, Data de Publicação: 14/08/2012)

Nos casos onde o reconhecimento for tardio, o pretenso pai ou mãe precisa ser pelo menos 16 anos mais velho que o filho, além de se a criança for maior de 12 anos, a medida exige seu consentimento.

No documento, o campo filiação terá a indicação dos nomes dos pais, que podem ser heterossexuais ou homossexuais, e os avós maternos e paternos serão substituídos pela nomenclatura ascendentes. As mudanças validas para todo o território nacional tiveram que ser adaptadas até o primeiro dia do corrente ano, quando se tornou obrigatório o novo formato na certidão.

Nota-se que demonstrada à possibilidade do reconhecimento da multiparentalidade em face dos princípios da dignidade da pessoa humana e da efetividade e permitindo as mudanças nas certidões de nascimento bem como nas decisões dos grandes Tribunais, é-se levado a acreditar que o direito está evoluindo, ainda que de forma vagarosa, para uma adaptação a realidade social encontrada nos dias atuais. 


\section{CONCLUSÃO}

Em virtude dos fatos mencionados entende-se que o presente trabalho buscou esclarecer e apresentar um novo conceito de família, aceito atualmente pelo ordenamento jurídico e por tratar-se de um modo distinto, sofreu bastante represália pelos olhos dos mais conservadores. Dado o exposto a nova possibilidade jurídica conferida aos genitores afetivos se sobrepõe aos sanguíneos.

Com o desenvolvimento do presente estudo possibilitou a ampliação na constituição de família e a adaptação da certidão de nascimento, visando o melhor interesse desta.

Observa-se que dessa forma ainda não há uma legislação específica para tal direito, no entanto essa evolução já pode ser considerada um grande avanço no Direito de Família.

Verifica-se ainda, que há requisitos a ser seguidos no que tange a certidão multiparental, pois deve haver primordialmente o interesse do menor, e não somente da mãe ou do pai.

Dessarte, o reconhecimento jurídico da multiparentalidade e sua exteriorização, por meio da averbação no registro civil, efetiva a garantia de todos os direitos advindos da pluralidade de pais/mães.

\section{REFERÊNCIAS}

BRASIL. Constituição (1988). Constituição da República Federativa do Brasil. 8. ed. São Paulo: Manoele, 2016.

TEIXEIRA, Ana Carolina Brochado; RODRIGUES, Renata de Lima. O direito das famílias: entre a norma e a realidade. São Paulo: Atlas, 2010.

BRASIL. Conselho Nacional de Justiça. Provimento no 63, de 14 de novembro de 2017 a. Disponível em: < http://www.cnj.jus.br/busca-atos-adm?documento=3380>Acesso em: 17 Jul. 2018.

CORRÊA, Leandro Augusto Neves et ali. Averbação da sentença de multiparentalidade: aplicabilidade. Disponível em: <http://www.recivil.com.br/preciviladm/modulos/artigos/documentos/artigo\%20multiparentalida de\%20averba\%C3\%A7\%C3\%A3o.pdf>. Acesso em: 15 jun. 2018.

DIAS, Maria Berenice. Manual de Direito das Famílias. 9ạ ed. rev., atual. e ampl. São Paulo: Revista dos Tribunais, 2013.

RONDÔNIA. Tribunal de Justiça do Estado. Processo n. 0012530-95.2010.8.22.0002. Juíza de Direito: Deisy Cristhian Lorena de Oliveira Ferraz. Decisão: 13 Mar. 2012. Disponível em: . Acesso em: 14 Jul. 2018.

KIRCH, Aline Taiane; COPATTI, Lívia Copelli. O reconhecimento da multiparentalidade e seus efeitos jurídicos. In: Âmbito Jurídico, Rio Grande, XVI, n. 112, maio 2013. Disponível em: <http://www.ambitojuridico.com.br/site/index.php/?n_link=revista_artigos_leitura\&artigo_id=12 754\&revista_caderno=14>. Acesso em ago 2018.

SÃO PAULO, Tribunal de Justiça do Estado, Processo n. 64222620118260286 SP $0006422-$ 26.2011.8.26.0286, Relator: Alcides Leopoldo e Silva Júnior Data de Julgamento: 14/08/2012, 1a Câmara de Direito Privado, Data de Publicação: 14/08/2012) disponível em: <http://tjsp.jusbrasil.com.br/jurisprudencia/22130032/ape lacao-apl-64222620118260286-sp-0006422-2620118260286-tjsp> acesso em 07 Ago. 2018. 
DIAS, Maria Berenice et ali. Multiparentalidade: uma realidade que a Justiça começou a admitir. Disponível em: http://www.mariaberenice.com.br/artigos.ph p?cat= \&subcat=\&termobusca=\&ordem=mais_antigos\&pagina=35. Acesso em: 08 Ago. 2018. 